\title{
Cost-effectiveness of mandatory folate fortification $v$. other options for the prevention of neural tube defects: results from Australia and New Zealand
}

\author{
Kim Dalziel*, Leonie Segal and Rachelle Katz \\ Health Economics, Division of Health Sciences, University of South Australia, GPO Box 2471, Adelaide, \\ South Australia 5001, Australia
}

Submitted 10 March 2008: Accepted 29 July 2009: First published online 17 September 2009

\begin{abstract}
Objective: To provide input to Australian and New Zealand government decision making regarding an optimal strategy to reduce the rate of neural tube defects (NTD).

Design: Standard comparative health economic evaluation techniques were employed for a set of intervention options for promoting folate/folic acid consumption in women capable of or planning a pregnancy. Evidence of effectiveness was informed by the international literature and costs were derived for Australia and New Zealand.

Results: Population-wide campaigns to promote supplement use and mandatory fortification were the most effective at reducing NTD, at an estimated 36 and 31 fewer cases per annum respectively for Australia and New Zealand, representing an $8 \%$ reduction in the current annual NTD rate. Population-wide and targeted approaches to increase supplement use were cost-effective, at less than \$AU 12500 per disability-adjusted life year (DALY) averted (\$US 9893, £5074), as was extending voluntary fortification. Mandatory fortification was not costeffective for New Zealand at \$AU 138500 per DALY (\$US 109609, £56 216), with results uncertain for Australia, given widely varying cost estimates. Promoting a folate-rich diet was least cost-effective, with benefits restricted to impact on NTD. Conclusions: Several options for reducing NTD appear to fall well within accepted societal cost-effectiveness norms. All estimates are subject to considerable uncertainty, exacerbated by possible interactions between interventions, including impacts on currently effective strategies. The Australian and New Zealand governments have decided to proceed with mandatory fortification; it is hoped they will support a rigorous evaluation which will contribute to the evidence base.
\end{abstract}

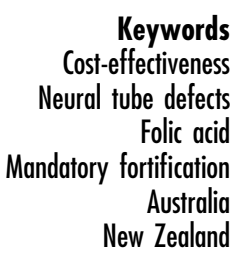

Neural tube defects (NTD; spina bifida, anencephaly and encephalocele) are a group of birth defects which occur in utero during the development of the brain and spinal cord. Observational studies and randomised trials have demonstrated a preventive effect of folic acid supplementation during the periconceptional period on the occurrence of NTD. A Cochrane review by Lumley et al. ${ }^{(1)}$ estimated a $72 \%$ reduction in the incidence of NTD with periconceptional folate supplementation, a relative risk of $0 \cdot 28(95 \%$ CI $0 \cdot 13,0 \cdot 58)$.

Internationally, there appears historically to be a reducing trend and more recently a plateau in the rates of NTD, with the largest drop from 45 per 10000 live and still births in 1980 to 10 per 10000 live and still births in 2000 reported for the $\mathrm{UK}^{(2)}$, although comparisons across countries and over time are compromised by variable definitions, reporting, ascertainment, diagnoses and termination of pregnancies ${ }^{(3)}$. There are known inconsistencies in the
Australian and New Zealand data on rates of NTD, with widely accepted best estimates for 1999-2003 of 1.32 per 1000 total births and 2.56 per 1000 births in 1996-2000 for Indigenous Australians ${ }^{(4)}$.

Australian and New Zealand guidelines are similar to those elsewhere ${ }^{(5,6)}$ and recommend that women planning or capable of becoming pregnant should consume folic acid as a supplement or in the form of fortified foods at a level of $400 \mu \mathrm{g} / \mathrm{d}$ for at least one month before and three months after conception, in addition to consuming food folate from a varied $\operatorname{diet}^{(7)}$. Periconceptional supplement use in Australia is estimated at $36 \%{ }^{(8)}$, with lower rates for Indigenous Australian women (see technical report for further details $\left.{ }^{(9)}\right)$. In Australia approximately $60 \%$ of pregnancies are planned, although definitions vary ${ }^{(8)}$.

A range of approaches have been used in Australia, New Zealand and elsewhere to promote consumption of periconceptional folic acid consistent with recommended 
guidelines. Voluntary fortification of specified foods with folic acid was first approved in Australia and New Zealand in 1995 and 1996, respectively. In 1999, more than 100 folate-fortified foods (predominantly breakfast cereals, fruit juices and breads) were reported to be available in Australia (with fewer in New Zealand). It was estimated that in 2006 mean folic acid intake for women aged 16-44 years from fortified foods was $108 \mu \mathrm{g} / \mathrm{d}$ in Australia and $62 \mu \mathrm{g} / \mathrm{d}$ in New Zealand ${ }^{(10,11)}$. Data from one Australian study analysing data for the states with adequate quality data (South Australia, Western Australia and Victoria) indicated a drop in NTD of 10-30\% since the introduction of voluntary folic acid fortification, although precise impacts are difficult to ascertain ${ }^{(3)}$.

In addition, mean daily natural folate intake from food for females aged 19-44 years has been estimated at $230 \mu \mathrm{g}$ in Australia in 1995 and $211 \mu \mathrm{g}$ in New Zealand ${ }^{(12,13)}$. Foods naturally high in folate include green leafy vegetables, legumes and oranges.

Campaigns to promote use of supplements by women planning or capable of a pregnancy have occurred intermittently over recent decades, following randomised controlled trials published in the early 1990s demonstrating the benefits $^{(1)}$. These campaigns and incorporation of advice into standard clinical practice have seen a rise in women taking folic acid supplements as recommended from 19·1\% in 1993 to $43 \cdot 1 \%$ in 1995 in Western Australia ${ }^{(14)}$.

Possibly due to these initiatives, reported NTD have fallen from 1.43 per 1000 total births in 1999 to 1.18 per 1000 live births in $2003^{(4)}$ (based on data from Western Australia, South Australia and Victoria), amounting to $0 \cdot 12 \%$ of all births in 2003. However, NTD remain a cause of considerable burden for the individual and families affected and society (both in health service costs and lost potential).

Mandatory fortification of a suitable staple has been proposed as a way to further reduce the rate of NTD. Mandatory fortification has been introduced at varying levels in up to fifty countries and has been evaluated in the USA, Chile, Costa Rica and Canada. The question we sought to address was whether mandatory fortification represents an effective and cost-effective means to further reduce NTD for Australia and New Zealand, relative to other options. The results of the analysis were made available to government to contribute to their decision-making processes.

\section{Methods}

The approach adopted was that of comparative cost-effectiveness analysis involving the following research tasks.

1. Identification of potential interventions through a literature review and consultation with government authorities, and selection of a subset for inclusion in an economic evaluation exercise.

2. Assessment of the quality of seminal studies that could be used to inform an economic evaluation of interventions.
3. Comparison of economic performance of the interventions through:

(a) the conduct of incremental cost-effectiveness analyses (with each intervention relative to current practice or status quo), with performance expressed as cost per NTD averted over a 10-year time horizon; and

(b) modelled cost-utility analyses, expressed as cost per disability-adjusted life year (DALY) averted over full life expectancy, with results presented with and without downstream savings to the health sector.

\section{Selection of interventions}

Extending voluntary and mandatory fortification were the current policy proposals against which other options were to be analysed. The attributes of the voluntary and mandatory fortification interventions were provided by Food Standards Australia New Zealand (FSANZ), based on extensive discussion and debate with industry. Alternative scenarios for extending current voluntary fortification permissions and mandatory fortification were also described for exploration through sensitivity analysis.

Standard databases including Medline, CINAHL and the Cochrane Database were searched to identify other potential interventions for promoting folate intake using subject headings and text words for folic acid, folate, dietary folate, neural tube defect and dietary supplements. Other potential interventions fell into two broad categories: (i) promotion of use of folic acid supplements in women who may become pregnant; and (ii) strategies to increase natural dietary folate consumption. Selection of interventions was made based on the following criteria: clear description of the intervention, good scientific rigor (ideally randomised controlled trials) and applicability to the Australian and New Zealand setting. Five studies on supplements and eleven studies on dietary folate were examined in detail. The aim was to include a mix of intervention types; specifically both population-wide and targeted interventions for promoting use of folic acid supplements in women who may become pregnant and to promote intake of dietary folate.

\section{Interventions selected}

Four broad types of intervention option for reducing the incidence of NTD were selected for analysis, each with a small number of variations. While each option was considered in isolation, it is recognised that interventions might best be implemented in combination. The intervention options subject to economic analysis were the following.

1. Promoting the use of folic acid supplements at least one month prior to and three months following conception through:

(a) a multifaceted general population campaign;

(b) a targeted campaign to disadvantaged women; or

(c) brief clinician advice to women aged $18-48$ years at a visit to an obstetrician/gynaecologist. 
2. Extending (and maintaining) voluntary fortification of the food supply with folic acid through the addition or extension of the following foods: bread, wholemeal flour, pasta, low-fat milk, low-fat yoghurt, low-fat and low-sugar biscuits, and juices. Modelling three separate scenarios: low industry, medium and higher 'optimistic', reflecting differing levels of uptake and permission.

3. Promoting consumption of folate-rich foods naturally and fortified through:

(a) a population-wide marketing campaign; or

(b) a targeted approach delivered in a clinical setting.

4. Mandatory folic acid fortification of wheat flour for bread-making, to $200 \mu \mathrm{g}$ folic acid/100 g flour in Australia and $135 \mu \mathrm{g}$ folic acid $/ 100 \mathrm{~g}$ bread in New Zealand.

The economic evaluation of each intervention was based on a seminal study which provided the primary source for effectiveness data and types of cost inputs. This approach was most appropriate given the highly individualised nature of each intervention. Seminal study details are summarised in Table 1.

\section{Quality assessment of seminal studies}

The quality of the seminal studies used to inform the economic evaluation of interventions was critically appraised broadly using the framework from the Centre for Reviews and Dissemination ${ }^{(15)}$. There were a number of concerns regarding the quality of the seminal studies, which have been reported in detail previously ${ }^{(9)}$.

\section{Economic evaluation}

Cost-effectiveness and cost-utility analyses were completed for each intervention, separately for Australia and New Zealand. Cost-utility results are presented as cost per DALY averted. A 10-year time frame was used for the costeffectiveness analysis and full life expectancy for the costutility analysis.

\section{Costs}

The incremental costs of each intervention (see Tables 2 and 3) were measured by differential resource use for intervention compared with control populations or participants, where costs were calculated as the product of: (i) programme inputs for the intervention and control protocols described in the study reports or provided by experts, including programme administrators, health professionals, materials and folic acid supplements, etc.; and (ii) Australian published or estimated unit costs (e.g. taken from the Medicare Benefits Schedule ${ }^{(16)}$ and a sample of pharmacies). Other types of costs included the cost of folic acid, training, equipment and supplies.

For the national campaigns, budget estimates were based on similar-scale national campaigns (such as the National Tobacco Campaign ${ }^{(17)}$, Skin Cancer Awareness ${ }^{(18)}$, Go for $2 \& 5^{(19)}$ and road safety ${ }^{(20)}$ ).
Submissions from food companies were drawn on to derive estimates for the cost of extending voluntary fortification (under three separate scenarios), with further information reported in detail previously ${ }^{(9)}$. For mandatory fortification, two cost estimates were used, one derived by a FSANZ-commissioned consultant and another derived by the flour industry ${ }^{(11)}$. These cost estimates vary considerably and have been used to derive two alternative sets of estimates of economic performance, a high cost estimate labelled as 'industry lower' and a low cost estimate labelled 'higher optimistic'.* We explored the implication of including a cost for loss of consumer choice, inevitably associated with mandatory fortification, at a minimal $\$ 1$ per person per year in sensitivity analyses. We also allowed for a scenario that included costs for monitoring and evaluation in sensitivity analysis. A more detailed explanation of costs used is contained in the technical report ${ }^{(9)}$.

\section{Outcomes}

Key effectiveness data, in terms of mean change in folic acid intake, were taken from the seminal studies for the supplement and natural dietary folate interventions and as derived by FSANZ ${ }^{(11)}$ for the extended voluntary (three scenarios) and mandatory fortification interventions. Table 4 shows the data used to inform the increases in folic acid intake for the supplement use interventions. For the natural dietary interventions, increases in natural folate were converted into dietary folate equivalents (DFE) by dividing by $1 \cdot 7$. This adjusts for a greater bioavailability of folic $\operatorname{acid}^{(7)}$.

Annual cases of NTD prevented were estimated from mean change in folic acid levels through replication of a published model ${ }^{(4)}$, calibrated for Australian and New Zealand women. A separate model was devised by FSANZ for Indigenous women. The model allows for estimation of confidence intervals which were used in sensitivity analyses. Key effectiveness results used in the economic model are reported in Tables 2 and 3 and are described in more detail in the technical report ${ }^{(9)}$. Possible benefits from folate enhancement or proposed dietary changes additional to the effect on NTD have been excluded from this evaluation, as have potential negative consequences.

The following key assumptions were used in the base case model:

1. Costs and outcomes discounted at $5 \%$ per annum, $0 \%$ used in sensitivity analyses.

2. Ten-year time horizon.

3. Bioavailability of folic acid taken as a supplement is $100 \%$, with $85 \%$ modelled in sensitivity analyses (bioavailability of natural dietary folate is approximately

* Note that these alternatives vary only in terms of costs, not effectiveness. 
Table 1 Details of interventions and seminal studies

\begin{tabular}{|c|c|c|}
\hline Intervention & $\begin{array}{c}\text { Target and sample frame for } \\
\text { evaluation }\end{array}$ & Description of intervention \\
\hline $\begin{array}{l}\text { Supplement use } \\
\text { WA Health } \\
\text { promotion } \\
\text { campaign }^{(14,50)}\end{array}$ & $\begin{array}{l}\text { Target: all women in WA of } \\
\text { childbearing age or considering } \\
\text { becoming pregnant } \\
\text { Sample frame, 1993: age 17-43 } \\
\text { years (mean } 28 \cdot 7 \text { ), } 86 \% \\
\text { married/de facto, } 83 \% \text { born in } \\
\text { Australia, NZ or UK, } 58 \% \text { high } \\
\text { school only, } 11 \% \text { technical/ } \\
\text { further, } 29 \% \text { university, } 36 \% \\
\text { first pregnancy, } 61 \% \text { planned } \\
\text { pregnancy } \\
\text { Sample frame,1995: similar to } \\
\text { above }\end{array}$ & $\begin{array}{l}\text { Key message: raise awareness of folate \& NTD, M } \\
\uparrow \text { women's folate intake } \\
\text { Physicians, pharmacists, dietitians, community } \\
\text { and child health workers - information sheets, } \\
\text { pamphlets, posters, articles in journals, } \\
\text { newsletters and bulletins, presentations, } \\
\text { training \& continuing education, stickers for } \\
\text { folic acid bottles, printed paper bags, } \\
\text { consumer newsletter } \\
\text { General community - seminars, message on } \\
\text { Medicare cheques, magazine articles, } \\
\text { newspaper, radio and TV ads, editorials, taxi } \\
\text { back ads, information sheet to public libraries, } \\
\text { displays and food demonstrations, cooking } \\
\text { programme \& education package, information } \\
\text { to education department and schools, } \\
\text { incorporating material into curriculum, public } \\
\text { launch, stamp, stickers, price tags }\end{array}$ \\
\hline
\end{tabular}

Houston Program Education \& free supplements for minority young
women $^{(51)}$
Target: young women from minority groups

Sample frame: age 13-22 years (mean 18), 93\% single, $72 \%$ black, $28 \%$ Hispanic, $59 \%$ education appropriate for age, $43 \%$ previous pregnancy, $86 \%$ sexually active in last 3 months \& not pregnant

Physician advice Arkansas, USA ${ }^{(52)}$

Dietary folate Targeted natural dietary folate education campaign $^{(53)}$

Target: women presenting for routine ob/gyn consultation

Sample frame: intervention group - mean age 29 years, $52 \%$ education, $15 \%$ graduate school, $58 \%$ income < $<$ US 30000 ; control group - similar except $9 \cdot 3 \%$ graduate school

\section{National health promotion} campaign $^{(54)}$
Target: healthy men and women living in South Wales, UK Sample frame: mean age 41 years, not currently taking folic acid supplements black, $45 \%$ single, $50 \%$ college

A trained health educator saw young women and asked them to complete an assessment questionnaire that assessed baseline knowledge on NTD, folic acid and intake. Young women were seen in hospital- or community-based free reproductive health clinics. The young women received personalised education regarding NTD, NTD prevention by folic acid, importance of taking daily supplements \& increasing consumption of natural \& fortified folate-rich foods. Young women also received a free 3month supply of multivitamin tablets

Women attending routine gynaecological consultation received brief (30-60 s) counselling regarding folic acid, a starter bottle of 30 supplements \& a pamphlet about benefits of folic acid. Women received a booster phone call from the research nurse 1-2 weeks after their visit. Control women received $30-60 \mathrm{~s}$ of counselling on another preventive health behaviour \& a pamphlet on folic acid containing a voucher for free supplements. Physicians were not prohibited from including folic acid advice to control women

Three dietary interventions:

Control diet - subjects were advised to eat their normal diet

Fortified diet - subjects were advised to eat an extra $100 \mu \mathrm{g}$ folic acid/d from fortified food products including cereals and breads

Natural folate diet - subjects were advised to eat an extra $100 \mu \mathrm{g}$ folate/d from natural sources, particularly fruit and vegetables, and to maintain normal consumption of fortified products

All subjects completed 2-week folate diary at baseline, 2 months and 4 months

Target: primarily parents and carers of children and youths aged $0-17$ years, with a secondary target of children aged 5-12 years and youth

Intervention details are assumed to be similar to the WA health promotion campaign for folate (see above for details)
Actual/potential settings

Media, pharmacists, supermarkets, professional seminars/workshops, general practitioners, paediatricians, obstetricians and gynaecologists, child health nurses, schools, child care centres, libraries, family planning clinics

Health or community centres where young minority women present for visits with health workers of any type

Public \& private ob/gyn practices \& clinics in the community \& hospital/ outpatients settings. Other providers of ob/gyn care such as general practitioners, specialist nurses and midwives

Women of childbearing age attending general practitioners or gynaecologists. This could also include women planning a pregnancy
Media, pharmacists, supermarkets, professional seminars/workshops, general practitioners, paediatricians, obstetricians \& gynaecologists, child health nurses, schools, child care centres, libraries, family planning clinics 
Table 2 Summary table of base case results - Australia

\begin{tabular}{|c|c|c|c|c|c|c|c|c|}
\hline \multirow[b]{2}{*}{ Intervention } & \multirow[b]{2}{*}{$\begin{array}{l}\text { Discounted cost } \\
\text { per annum } \\
\text { (\$AU) }\end{array}$} & \multirow[b]{2}{*}{$\begin{array}{l}\text { Discounted net } \\
\text { costt }(\$ A U)\end{array}$} & \multirow[b]{2}{*}{$\begin{array}{l}\text { Mean increase in } \\
\text { folic acid per woman } \\
\text { per day }(\mu \mathrm{g})\end{array}$} & \multirow[b]{2}{*}{$\begin{array}{l}\text { NTD prevented } \\
\text { per annumt } \\
\text { (discounted) }\end{array}$} & \multirow[b]{2}{*}{$\begin{array}{l}\text { Discounted } \\
\text { reduction in } \\
\text { DALY† }\end{array}$} & \multirow[b]{2}{*}{$\begin{array}{c}\text { Discounted cost } \\
\text { per NTD } \\
\text { prevented }(\$ A U)\end{array}$} & \multicolumn{2}{|c|}{$\begin{array}{c}\text { Discounted cost per DALY averted (net } \\
\text { cost offsets) }+(\$ A U)\end{array}$} \\
\hline & & & & & & & Base case & $\begin{array}{l}\text { Range from sensitivity } \\
\text { analysis }\end{array}$ \\
\hline \multicolumn{9}{|l|}{ Supplement use } \\
\hline Health promotion campaign & 1153126 & 20513724 & 119 & $27 \cdot 1(21 \cdot 0)$ & 2243 & 55000 & 9100 & 3300 to 18900 \\
\hline Minority young women & 233670 & 2005818 & 129 & $5(3.9)$ & 163 & 60500 & 12300 & 4800 to 21900 \\
\hline Physician advice & 232563 & 4076215 & 91 & $13 \cdot 1(10 \cdot 1)$ & 1080 & 23100 & 3800 & 500 to 10000 \\
\hline \multicolumn{9}{|l|}{$\begin{array}{l}\text { Extended voluntary } \\
\text { permissions }\end{array}$} \\
\hline Medium scenario & 81466 & 654124 & 24 & $7 \cdot 1(5 \cdot 5)$ & 585 & 14900 & 1100 & Intervention dominates \\
\hline Industry lower scenario & 32586 & 371323 & 6 & $1.8(1.4)$ & 149 & 23400 & 2500 & to 8200 \\
\hline Higher 'optimistic' scenario & 230625 & 3486312 & 38 & $11 \cdot 2(8.6)$ & 927 & 26700 & 3800 & \\
\hline \multicolumn{9}{|l|}{ Mandatory fortification } \\
\hline $200 \mu \mathrm{g} / 100 \mathrm{~g}$ flour, low cost & 1552408 & 26995208 & 85 & $23 \cdot 8(18 \cdot 4)$ & 1970 & 84400 & 13700 & 9500 to 177200 \\
\hline $200 \mu \mathrm{g} / 100 \mathrm{~g}$ flour, high cost & 11351261 & 262291544 & 85 & $23 \cdot 8(18 \cdot 4)$ & 1970 & 617400 & 133100 & 95700 to 296600 \\
\hline \multicolumn{9}{|l|}{ Dietary folate } \\
\hline $\begin{array}{l}\text { Targeted campaign - } \\
\text { natural folate }\end{array}$ & 1038461 & 23688634 & 29 & $2 \cdot 2(1 \cdot 7)$ & 180 & 619700 & 131900 & 2400 to 300900 \\
\hline $\begin{array}{l}\text { Targeted campaign - all } \\
\text { folate }\end{array}$ & 1038461 & 25365252 & 74 & $5 \cdot 3(4 \cdot 1)$ & 435 & 255700 & 58300 & 5400 to 103200 \\
\hline $\begin{array}{l}\text { National health promotion } \\
\text { campaign - natural }\end{array}$ & 1153126 & 22935499 & 15 & $4 \cdot 4(3 \cdot 4)$ & 365 & 338600 & 62900 & 20700 to 140100 \\
\hline $\begin{array}{l}\text { National health promotion } \\
\text { campaign - all folate }\end{array}$ & 1153126 & 22366862 & 54 & $9 \cdot 7(7 \cdot 5)$ & 806 & 153300 & 27800 & 15300 to 55300 \\
\hline
\end{tabular}

NTD, neural tube defects.

*Average over 10 years divided by 10 .

tModelled to life expectancy.

¥Modelled over 10 years. 
Table 3 Summary table of base case results - New Zealand

\begin{tabular}{|c|c|c|c|c|c|c|c|c|}
\hline \multirow[b]{2}{*}{ Intervention } & \multirow[b]{2}{*}{$\begin{array}{l}\text { Discounted cost } \\
\text { per annum* } \\
(\$ N Z)\end{array}$} & \multirow[b]{2}{*}{$\begin{array}{l}\text { Discounted net } \\
\text { costt (\$NZ) }\end{array}$} & \multirow[b]{2}{*}{$\begin{array}{l}\text { Mean increase in } \\
\text { folic acid per woman } \\
\text { per day }(\mu \mathrm{g})\end{array}$} & \multirow[b]{2}{*}{$\begin{array}{l}\text { NTD prevented } \\
\text { per annumt } \\
\text { (discounted) }\end{array}$} & \multirow[b]{2}{*}{$\begin{array}{l}\text { Discounted } \\
\text { reduction in } \\
\text { DALY† }\end{array}$} & \multirow[b]{2}{*}{$\begin{array}{c}\text { Discounted cost } \\
\text { per NTD } \\
\text { prevented }(\$ N Z)\end{array}$} & \multicolumn{2}{|c|}{$\begin{array}{c}\text { Discounted cost per DALY averted (net } \\
\text { cost offsets) }+(\$ N Z)\end{array}$} \\
\hline & & & & & & & Base case & $\begin{array}{l}\text { Range from sensitivity } \\
\text { analysis }\end{array}$ \\
\hline \multicolumn{9}{|l|}{ Supplement use } \\
\hline Health promotion campaign & 258554 & 4662522 & 190 & $8 \cdot 7(6 \cdot 7)$ & 722 & 38400 & 6500 & 3200 to 11900 \\
\hline Physician advice & 52145 & 943765 & 146 & $4 \cdot 2(3 \cdot 2)$ & 348 & 16100 & 2700 & \\
\hline \multicolumn{9}{|l|}{$\begin{array}{l}\text { Extended voluntary } \\
\text { permissions }\end{array}$} \\
\hline Medium scenario & 18266 & 113662 & 48 & $3 \cdot 0(2 \cdot 3)$ & 249 & 7900 & 500 & Intervention dominates \\
\hline Industry lower scenario & 7307 & -602 & 29 & $1.9(1.5)$ & 156 & 5000 & Cost saving & to 3000 \\
\hline Higher 'optimistic' scenario & 51711 & 790410 & 63 & $3.9(3.0)$ & 319 & 17300 & 2500 & \\
\hline \multicolumn{9}{|l|}{ Mandatory fortification } \\
\hline $135 \mu \mathrm{g} / 100 \mathrm{~g}$ bread & 2966437 & 79524528 & 119 & $6 \cdot 9(5 \cdot 4)$ & 574 & 553600 & 138500 & 79700 to 251300 \\
\hline \multicolumn{9}{|l|}{ Dietary folate } \\
\hline $\begin{array}{l}\text { Targeted campaign - } \\
\text { natural folate }\end{array}$ & 232844 & 5781661 & 29 & $0.5(0.4)$ & 39 & 641600 & 148700 & 14700 to 701700 \\
\hline $\begin{array}{l}\text { Targeted campaign - all } \\
\text { folate }\end{array}$ & 232844 & 5737340 & 74 & $1 \cdot 1(0 \cdot 9)$ & 94 & 266900 & 61400 & 6200 to 139700 \\
\hline $\begin{array}{l}\text { National health promotion } \\
\text { campaign - natural }\end{array}$ & 258554 & 5184295 & 15 & $1 \cdot 0(0 \cdot 7)$ & 79 & 352500 & 66000 & 20300 to 316300 \\
\hline $\begin{array}{l}\text { National health promotion } \\
\text { campaign - all folate }\end{array}$ & 258554 & 5024473 & 33 & $3 \cdot 3(2 \cdot 6)$ & 276 & 100600 & 18200 & 9800 to 62600 \\
\hline
\end{tabular}

NTD, neural tube defects.

*Average over 10 years divided by 10 .

tModelled to life expectancy.

¥Modelled over 10 years. 
Table 4 Scenarios for changes in supplement use

\begin{tabular}{|c|c|c|c|c|}
\hline Scenario & Baseline (\%) & $\begin{array}{l}\text { Follow-up } \\
(\%)\end{array}$ & $\begin{array}{l}\text { Absolute percentage } \\
\text { point change }\end{array}$ & Application \\
\hline \multicolumn{5}{|l|}{ Population-wide health promotion campaign } \\
\hline WA results as presented & 14 & $30 \cdot 6$ & $16 \cdot 6$ & Base case* \\
\hline WA results minus women with planned pregnancies & $2 \cdot 1$ & $12 \cdot 2$ & $10 \cdot 1$ & Sensitivity estimate \\
\hline Results from SA campaign (plus national campaign) & $10 \cdot 1$ & $46 \cdot 1$ & $36 \cdot 6$ & Sensitivity alternative \\
\hline \multicolumn{5}{|l|}{ Houston Program Education } \\
\hline At least 21 times per month & 9 & 27 & 18 & Base case* \\
\hline Base case halved & & & 9 & Sensitivity lower estimate \\
\hline Results from Georgia study & 23 & 42 & 19 & Sensitivity alternative \\
\hline \multicolumn{5}{|l|}{ Physician advice } \\
\hline Intervention group results & $23 \cdot 7$ & $39 \cdot 6$ & $15 \cdot 9$ & Base case* \\
\hline Control group results & $23 \cdot 6$ & $36 \cdot 4$ & $12 \cdot 8$ & Sensitivity alternative \\
\hline
\end{tabular}

WA, Western Australian; SA, South Australian.

${ }^{*}$ As reported in the seminal trial. It is also similar to the reported result of a 1995 population-based campaign in The Netherlands to promote folic acid supplement use $\mathrm{e}^{(55)}$

$50-60 \%$, whereas folic acid used to fortify foods is approximately $85 \%$ bioavailable; on an empty stomach, folic acid as a supplement is almost 100\% bioavailable).

4. Thirty per cent of the target group currently takes supplements, 9\% for Indigenous women.

5. Average dose of folic acid as a supplement is $500 \mu \mathrm{g} / \mathrm{d}$ in Australia and $800 \mu \mathrm{g} / \mathrm{d}$ in New Zealand owing to these being the formulations available (see technical report for further details $\left.{ }^{(9)}\right)$.

6. Folate intake from other sources remains constant.

7. For the supplement interventions, additional supplement use is spread evenly across the $70 \%$ of women assumed not to be already taking supplements.

8. For the voluntary and mandatory scenarios, increased folate levels are applied to population means.

9. Costs include a combination of year 1 costs plus ongoing costs to maintain the impact.

\section{Economic modelling for cost utility}

Evidence on costs and effectiveness were used to calculate a cost per DALY averted, modelled to full life expectancy with and without estimated change in downstream treatment costs incurred by the health sector. The DALY, while less commonly used than the qualityadjusted life year (QALY) ${ }^{(21)}$, is a measure derived by the World Bank and WHO primarily to measure global health status/disease burden as a combined measure of premature mortality and disability.* The Dutch disability weights used were derived through panels of medical experts making valuations of health conditions with some statistical interpolation for additional states not directly valued $^{(22)}$. Disability weights are expressed from 1 to 0 , where 1 is total disablement or death and 0 is full health. NTD prevented were classified into live births (19\%), still births (11\%) and terminations (70\%), with a disability weight for live NTD births surviving past age 1 (a proportion

* Note that the use of the term 'disability' in DALY differs from its common use in public health ${ }^{(21)}$. of those with spina bifida and enencephalocele) of $0.52^{(23)}$. There is no published disability weight for termination, only for an abortion which is 0 . We have assumed a disability weight of 0.01 for terminations, while still births, all those born with anencephaly and those born with spina bifida or enecephalocele who did not survive past age 1 were counted as a full loss of life (i.e. weight of 1). These disability weights were applied to the estimated reduction in cases of NTD to calculate the change in DALY and used to estimate the cost per DALY averted. Each intervention was modelled with and without the inclusion of net downstream costs associated with future health costs for persons with an NTD as taken from publicly reported 2005 Australian estimates $^{(24)}$. The cost offset for spina bifida was based on the cost of terminations, maternal care, hospital presentations and admissions, pathology, imaging, pharmaceuticals, visits to specialists and allied health professionals, using official Australian Institute of Health and Welfare and Medicare statistics. $\uparrow$ A weighted average cost for all NTD was based on a combination of thoracic/high lumbar, low lumbar and sacral spina bifida lesions derived in consultation with experts. Owing to the small number of cases of encephalocele, the cost of spina bifida was used as a proxy for total health-care costs that would be avoided ${ }^{(24)}$. Estimates of \$AU 13500 (\$US 10684 , £5480; based on exchange rates at 1 March 2007) per annum for years 1 to 4 and \$AU 4354 (\$US 3446, £1767) for years 5 onwards were used ${ }^{(24)}$. The cost-utility analyses were modelled to full life expectancy, which was assumed to be 80 years (the average of 78 years for males and 82 years for females) ${ }^{(25)}$. All costs were expressed in 2006 values.

One-way sensitivity analyses were performed for key variables and assumptions, including: alternative effectiveness results (levels of increase in folic acid); reduced bioavailability of folic acid (85\%); a lower dose of folic acid supplement of $400 \mu \mathrm{g} / \mathrm{d}$; higher and lower cost

$\dagger$ It should be noted that costs may be underestimated due to inability to capture costs related to co-morbid events that may not have been classified as spina bifida-related. 
scenarios; the 5\% and $95 \%$ confidence intervals around the translation of folic acid increases into NTD prevented; and, for the mandatory fortification interventions, the inclusion of monitoring and evaluation costs and a cost of $\$ 1$ per person assigned to loss of consumer choice (see technical report for further details $\left.{ }^{(9)}\right)$. Sensitivity analyses also included the removal of encephalocele as an NTD potentially reduced through folic acid due to current debate $^{(26)}$, and increasing the disability weight assigned to encephalocele and spina bifida from 0.52 to 0.68 to reflect a more serious health state ${ }^{(23)}$. Probabilistic sensitivity analysis was not conducted because of a lack of robust data on error margins to inform distributions of included parameters.

\section{Results}

\section{Comparative effectiveness (neural tube defects avoided)}

The estimated effects on the number of NTD for each of the twelve proposals modelled for Australia and the eleven for New Zealand are presented in Tables 2 and 3, respectively. The greatest reductions in NTD were estimated for a population-wide health promotion campaign to promote folic acid supplement use in women who may become pregnant (27 NTD per annum for Australia, an $8 \%$ reduction; 9 per annum for New Zealand, a $12 \%$ reduction) and for mandatory fortification (24 NTD per annum for Australia and 7 per annum for new Zealand). Campaigns targeting natural dietary folate had least effect.

\section{Cost effectiveness (cost per neural tube defect avoided)}

Cost per NTD prevented (terminations, still births and live births) is reported for Australia and New Zealand in Tables 2 and 3, respectively. In relation to mandatory fortification of bread-making flour, we have modelled cost-effectiveness using both the cost estimate derived from the industry-commissioned study and the FSANZcommissioned study. This translates into a very large difference in the estimated cost-effectiveness of mandatory fortification in Australia, at \$AU 84000 (\$US 66478 , £34095) per NTD prevented using the FSANZ-commissioned estimate and \$AU 617000 (\$US 488 295, £250 434) per NTD prevented based on the industry-commissioned estimate. Thus, depending on what the actual costs are, mandatory fortification may perform poorly or 'reasonably' in terms of cost-effectiveness. For New Zealand mandatory fortification is unlikely to represent a costeffective option, estimated at over \$NZ 500000 per NTD prevented (\$US 352600, £180 839).

We also note that some initiatives that are not highly effective are relatively cost-effective as they are associated with relatively low costs (e.g. extended voluntary fortification). Proposals that perform relatively well in terms of effectiveness and cost-effectiveness include physician advice to promote supplement use.

Modelled cost-utility analysis (cost per disabilityadjusted life year modelled to full life expectancy) Cost-utility results are presented in Tables 2 and 3 for Australia and New Zealand, respectively, as \$ per DALY averted with and without the net treatment cost offsets. There is considerable uncertainty associated with these estimates as discussed below.

\section{Sensitivity analyses}

Results are highly sensitive to the selected assumptions, particularly the cost of the intervention and the $95 \%$ confidence interval for translating the changes in mean folic acid intake into NTD; further details are available in the technical report ${ }^{(9)}$. Results were not sensitive to the removal of encelphalocele as an NTD potentially reduced through folic acid, nor through increasing the disability weight associated with encephalocele and spina bifida from 0.52 to $0 \cdot 68$. Results summarized in Table 2 ranged from \$AU 3300 (\$US 2612, £1339) per DALY averted including cost offsets to \$AU 18900 (\$US 14957, £7671) for the supplement campaign; from \$AU 4800 (\$US 3799, $£ 1948$ ) to \$AU 21900 (\$US 17332, £8889) for a targeted supplement education intervention for Indigenous women; from \$AU 500 (\$US 396, £203) to \$AU 10000 (\$US 7914, £4059) for physician supplement advice; from intervention cheaper and more effective (dominates) to \$AU 8200 (\$US 6489, £3328) for extended voluntary fortification; from \$AU 95700 (\$US 75737, £38 844) to \$AU 296600 (\$US 234730, £120387) for mandatory fortification with high cost estimates included; from \$AU 9500 (\$US 7518, £3856) to \$AU 177200 (\$US 140236 , £71924) for mandatory fortification with low cost estimates included; from \$AU 2400 (\$US 1899, £.974) to \$AU 300900 (\$US 238133, £122132) for the dietary folate from natural sources only interventions; and from \$AU 5400 (\$US 4274, £2192) to \$AU 103200 (\$US 81673, £41888) for dietary folate from natural and fortified sources interventions. The results followed a similar trend for New Zealand; the main difference being mandatory fortification of bread, with results ranging from \$NZ 79700 (\$US 56204 , £28 826) to \$NZ 251300 per DALY averted including cost offsets (\$US 177217 , £.90 889).

These results can be compared with conventional thresholds that are commonly applied to guide decisions within other areas of health, such as for listing of pharmacotherapies by the Pharmaceutical Benefits Advisory Committee. In Australia a threshold of less than \$AU 40000 per QALY (\$US 31656, £16236) has been viewed as favourable for the decision to fund ${ }^{(27)}$. Funding through the Pharmaceutical Benefits Scheme is, however, predicated on high-quality evidence of effectiveness. In terms of cost per DALY averted for both Australia and New Zealand with cost offsets, extended voluntary 
permissions and promotion of supplement use appear cost-effective. The low cost mandatory fortification scenario also appears cost-effective for Australia, although this does not include the cost of monitoring or of a related public health campaign. For New Zealand mandatory fortification does not appear cost-effective.

\section{Discussion}

While a number of the interventions analysed appear costeffective, it is important to understand that none of the proposals in isolation would make a large impact on total NTD cases. Even the most effective involves less than a $10 \%$ reduction in total NTD cases. Furthermore, none of the proposals is expected to achieve the equivalent impact of current voluntary permissions in Australia of an estimated $15-30 \%$ reduction in NTD or of current policies to promote folate supplements for women planning a pregnancy, although, as noted below, the attribution of observed changes to specific policies is problematic.

The context in which policies are introduced will have a major influence on their impact. But relatively little is known about the reasons for the large falls in rates of NTD across much of Europe. The decline has been most rapid in the UK, where reported rates of NTD have fallen from 45 per 10000 live and still births in 1980 to 10 per 10000 live and still births in $2000^{(28)}$, with a continuing decline since then but at a lower rate. These large falls in rates of NTD have occurred without the introduction of mandatory fortification. A rigorous analysis of the international data to explain historic trends would be most useful. In its absence, the attribution of observed changes in NTD rates to specific strategies is unconvincing and poses considerable challenges for the monitoring of new policies.

Nevertheless, it is widely accepted that the promotion of supplement use by women planning (or capable of) a pregnancy must remain a core component of a strategy to minimise NTD. It is the only intervention supported by strong clinical trial evidence. It is critical that whatever policies are introduced do not affect current initiatives deleteriously, otherwise the net effect could potentially be an increase in the number of NTD cases. The likely impact of mandatory fortification on other strategy components, both existing and potential, is uncertain. Both positive and negative synergies are possible. For instance, if all bread is fortified consumers may lose interest in obtaining folate from other foods or even choose to avoid them; on the other hand, they may develop a greater interest in fortified foods. Similarly, in relation to folate supplements, women may think they are getting enough folate from bread and not take supplements or may become more aware of the value of folate and increase supplement use. The reported use of daily supplements containing folic acid according to national, random digit telephone surveys of women of childbearing age in the
USA is mixed, with reported rates of $32 \%$ in $2003,40 \%$ in $2004,33 \%$ in 2005 and $40 \%$ in $2007^{(29)}$. Another US study stresses that, even after fortification, taking folic acid supplements has a large effect of serum folate status and whether women are reaching recommended levels, and that racial differences remain despite fortification ${ }^{(30)}$. The US experience would suggest caution in governments placing total reliance on mandatory fortification. While we are not suggesting that this is advocated in countries with mandatory fortification, our concern is simply that with competing demands on government resources, funds for complementary programmes for promoting supplement use may be more at risk.

It will be important to monitor not just change in the rate of NTD but also changes in folate intake in non-target groups, as well as safety, particularly in children and the elderly, and which population group is benefiting. While monitoring of the introduction of mandatory fortification is identified by FSANZ as a priority, designing a robust evaluation is difficult, and a clear funding commitment will need to be made. Collection of high-quality baseline data on consumer dietary habits, folate levels and rate of NTD is necessary, but given the relatively small impact expected ( $\sim 8 \%$ of NTD averted), together with a wide range of possible confounders, it will be difficult to observe whether the policy is working.

\section{Comparisons witb existing literature and international experience}

Australia and New Zealand join approximately fifty other countries (including the USA, Canada and Chile) as countries that have proceeded with mandatory fortification of wheat flour with folic acid, although there is a distinction between low-level fortification and highlevel fortification intended to reduce $\mathrm{NTD}^{(31)}$. Reported reductions in NTD incidence range from $27 \%$ to $51 \%$, although evaluations have differing degrees of rigor. Since mandatory fortification was introduced in the USA in 1996 there has been an increase in mean folic acid intake of $200 \mu \mathrm{g} / \mathrm{d}$, which it is estimated has led to a $27 \%$ reduction in NTD along with net cost saving (cost offsets greater than programme cost $)^{(32-34)}$. Serum folate levels increased substantially by $119 \%$ in the first postfortification survey in the USA and then declined only slightly by $5-13 \%$ between the first and third postfortification surveys ${ }^{(35)}$. In Canada, following fortification in 1998, a $46 \%$ reduction in NTD-affected births has been reported, although this study excluded Ontario with the greatest number of births ${ }^{(36)}$. Chile mandated folic acid fortification in 2000; it was followed by a $51 \%$ decrease in the birth prevalence rate of spina bifida and a $42 \%$ decrease in the birth prevalence rate of anencephaly, which represented a significant decrease even when examining within the context of historical NTD trends ${ }^{(37)}$. Costa Rica fortified wheat flour in 1997 and corn flour in 1999; the national rate of NTD has reportedly dropped 
from $9 \cdot 7$ per 1000 live births (1996-8) to $6 \cdot 3$ per 1000 live births (1999-2000, post-fortification) ${ }^{(38)}$. The NTD incidence in a large hospital in Saudi Arabia decreased from 1.9 per 1000 live births (1997-2000, pre-fortification period) to 0.76 per 1000 live births (2001-5, post-fortification) following wheat fortification with folic acid ${ }^{(39)}$.

The international data may not be transferable between different countries as the magnitude in NTD decrease observed following mandatory fortification will be sensitive to the current population folate levels and use of supplements by women. The poorer the current folate status, the greater the potential for larger reductions in NTD, reflecting the non-linear relationship between folate level and NTD ${ }^{(40)}$. When mandatory fortification was introduced in the USA, mean total dietary folate intake (includes food folate and folic acid from fortification) was generally to be reported low, estimated at $275 \mu \mathrm{g} / \mathrm{d}^{(41)}$. This compares with the recent situation in Australia (and New Zealand) with estimated intake of $338 \mu \mathrm{g} / \mathrm{d}$ (composed of $230 \mu \mathrm{g} / \mathrm{d}$ from natural sources ${ }^{(12,13)}$ and an additional $108 \mu \mathrm{g} / \mathrm{d}$ from fortified food $\left.{ }^{(10,11)}\right)$. This reflects a successful voluntary fortification policy in Australia and New Zealand.

Economic evaluations of mandatory fortification with folic acid following its introduction have been performed for the USA ${ }^{(34)}$ and Chile ${ }^{(42)}$, and hypothetical economic evaluations prior to mandatory fortification have been performed for The Netherlands ${ }^{(43)}$ and the USA ${ }^{(44)}$. The most recent Netherlands evaluation used reported costs associated with folic acid food fortification from the USA translated into Euros, deflated to 2005 values and adjusted for country size. Their estimates of $€ 312000$ to $€ 2$ million (\$AU 519000 to $\$$ AU $3 \cdot 3$ million) per annum appear lower than our estimates of $\$ A U$ 7.9-28.6 million upfront and \$AU 1.2-12.7 million ongoing. One main difference in costs is attributed to the zero cost in the USA and The Netherlands for equipment compared with the Australian estimates of $\$ \mathrm{AU} 1 \cdot 4-22 \cdot 1$ million upfront, which reflects the more tightly regulated maximum folic acid levels that could not be obtained using existing fortification equipment. Another difference is that the Australian costs include government enforcement costs associated with training and awareness, audit and complaints management.

There is little international evidence on the cost-effectiveness of folic acid supplement campaigns. A study conducted in The Netherlands reported a net cost per discounted life year gained of $€ 1800$ ( $\$$ AU 2995), but the costs were limited to the cost of folic acid supplements and ignored the costs of policies to promote supplement use $^{(45)}$. That estimate is, however, consistent with our estimates of \$AU 3800-12300 for the supplement interventions, and we did include campaign and professional attendance costs.

There is currently no mandatory fortification with folic acid in Europe primarily due to concerns about loss of consumer choice and potential risks. The decision to mandate is still being considered in the UK, with previous decisions not to mandate.

\section{Limitations}

Our economic evaluation of interventions for the reduction of NTD is subject to limitations, primarily reflecting important gaps in the evidence base relating to both the effectiveness of potential interventions for promoting folate intake and costs. This reflects a lack of high-quality studies. Drawing on lessons from overseas, the impact of mandatory fortification will be confounded by differences in baseline characteristics, particularly in terms of already fortified foods, eating habits of the population, current folate status and patterns of folate supplement usage.

One area of uncertainty in the data is that the complex relationship between folic acid levels and NTD relies on a published model being a correct representation ${ }^{(4)}$. Another uncertainty is the level of folic acid increase that may be achieved given current supplement consumption patterns. While it is possible that a folic acid increase of 16 percentage points may not be realised from a populationwide campaign given current levels of folic acid intake, an increase of about 16 percentage points was reported from a number of studies, despite differing baseline levels of folic acid consumption. We have also explored a possible lower impact of a $10 \cdot 1$ percentage point increase, which not surprisingly shows a higher cost per DALY averted (net cost offsets) from \$AU 9100 to \$AU 13300 for Australia and from \$NZ 6500 to \$NZ 9100 for New Zealand, still indicating a highly cost-effective intervention.

The study is limited in scope in three ways. First, we are not confident that all plausible intervention options have been included; for example, an analysis of options for enhancing the nutrient quality of flour through more natural means such as aleurone flour, which contains minerals including folate ${ }^{(46)}$.

Second, outcomes have been limited to their effect on NTD and the associated DALY consequences with other possible benefits or negative consequences ignored. Research suggests that increasing folate levels may have broader health benefits than reducing NTD, such as lowering homocysteine levels associated with $\mathrm{CHD}^{(47)}$. Evidence remains conflicting and therefore other potential benefits have not been included.

Third, we have been unable to evaluate combinations of interventions and adjust for interactions between strategies. The nature of the relationships between intervention elements is not sufficiently well understood to support such an analysis. However, this is ideally required to devise a preferred suite of policy instruments.

Generalised cost-effectiveness analysis (GCEA) is an alternative approach used for sector-wide or national priority setting that is predominantly applied in developing countries. It involves comparing all interventions to a 'null scenario' ${ }^{,(48,49)}$, although this is not always feasible 
or desirable. For the present study incremental costeffectiveness analysis (ICEA) was used, given the policy context and the clear expectation from government that existing strategies to promote folate use remain. For the same reason we also did not consider possible decrements (even though this is easily incorporated into ICEA).

\section{Future research}

A decision was made to proceed with mandatory fortification in Australia and New Zealand in July 2007 with a 2-year introductory period. A rigorous monitoring and evaluation of this action, to ascertain costs and outcomes on folate intake in both target and non-target populations and NTD, is highly desirable. This is especially so given the high level of uncertainty of the predictive analysis and the possible interaction between mandatory fortification and current effective strategies to reduce NTD.

It will be important that the impact on disadvantaged groups such as Indigenous women and women from low socio-economic backgrounds is studied specifically, as this appears to be an important part of the rationale for proceeding with mandatory fortification.

Fortification of the food supply highlights a wider research agenda concerning the nutrient quality of basic foods. Mandatory fortification with folic acid is partly designed to combat the nutrient depletion of staple foods, such as wheat, sugar and rice, through farming and refining processes that remove the nutrient-rich components. This is sometimes referred to as 'medicalisation' of the food supply. A possible alternative is to tackle nutrient quality at source. This is a broader public health issue with wide-ranging impacts. Rather than moving towards ever-growing single nutrient solutions, alternative means to reintroduce nutritional quality into staple foods should be explored.

\section{Conclusions}

There are a number of strategies which, taken in combination, can increase folate consumption and reduce the incidence of NTD. It is not clear, however, that we have all of the evidence available to inform an evidence-based national strategy, despite government decisions to proceed with mandatory fortification. Mandatory fortification appears slightly more effective than some strategies; it is estimated to reduce NTD by $8 \%$ at relatively high cost and lower cost-effectiveness than other options (such as a high-profile ongoing population-wide campaign to promote supplement use). Cost-effectiveness of mandatory fortification and other strategies appears to be significantly different in Australia and New Zealand, warranting individual implementation strategies.

Despite gaps in the evidence base and concerns about data quality, we can conclude that in terms of public heath policy, investing in cost-effective strategies to reduce NTD is a highly valued use of society's resources, based on estimates of DALY averted for resources expended. Investing in the promotion of folic acid supplement use in women planning (or capable of) a pregnancy will be part of any optimal strategy to reduce NTD, regardless of the decision to proceed with mandatory fortification. Moreover, to achieve the degree of equity for society that is likely to be desired, a sub-strategy targeting high-risk women is also indicated.

\section{Acknowledgements}

This work was performed as contract work performed for Food Standards Australia and New Zealand (FSANZ). We would like to thank FSANZ for comments on our draft report prepared prior to manuscript preparation and for the provision of data related to the mandatory and extended voluntary scenarios. We would like to thank FSANZ Chief Public Health Nutrition Advisor for provision of the first draft of a model linking folic acid intake to NTD prevented. The authors declare that they have no conflicts of interest. K.D., L.S. and R.K. all contributed to the design of the research, the conduct of the research, and drafting and revising the manuscript.

\section{References}

1. Lumley J, Watson L, Watson M \& Bower C (2001) Periconceptional supplementation with folate and/or multivitamins for preventing neural tube defects. Cochrane Database Syst Rev issue 3, CD001056.

2. European Surveillance of Congenital Anomalies (2005) Special Report: Prevention of Neural Tube Defects by Perioconceptional Folic Acid Supplementation in Europe. Northern Ireland: Eurocat.

3. Lancaster P \& Hurst T (2001) Trends in Neural Tube Defects in Australia. Canberra: AIHW National Perinatal Statistics Unit, University of New South Wales, Australian Food and Nutrition Monitoring Unit.

4. Bower C, DeKlerk N, Hickling S, Ambrosini G, Flicker L, Geelhoed E \& Milne E (2006) Assessment of the potential effect of incremental increases on folic acid intake on neural tube defects in Australia and New Zealand. Aust NZ J Public Health 30, 369-374.

5. Department of Health (1992) Folic Acid and the Prevention of Neural Tube Defects. Report from an Expert Advisory Group. London: HMSO.

6. Institute of Medicine, Food and Nutrition Board (1998) Dietary Reference Intakes: Thiamin, Riboflavin, Niacin, Vitamin $B_{6}$, Folate, Vitamin B $B_{12}$, Pantothenic Acid, Biotin, and Choline. Washington, DC: National Academy Press.

7. Australian Government, Department of Health and Ageing, National Health and Medical Research Council \& New Zealand Ministry of Health (2006) Nutrient Reference Values for Australia and New Zealand Including Recommended Dietary Intakes. Canberra: Commonwealth of Australia.

8. Conlin ML, MacLennan AH \& Broadbent JL (2006) Inadequate compliance with periconceptional folic acid supplementation in South Australia. Aust $N Z J$ Obstet Gynaecol 46, 528-533.

9. Segal L, Dalziel K\& Katz R (2007). A Report to FSANZ. Informing a Strategy for Increasing Folate Levels to Prevent 
Neural Tube Defects: A Cost-effectiveness Analysis of Options. http://www.foodstandards.gov.au/_srcfiles/P295_ Attachment_4_Professor_Segals_Report.pdf (accessed August 2009).

10. Bower C, Ryan A, Rudy E \& Miller M (2002) Trends in neural tube defects in Western Australia. Aust N ZJ Public Health 26, 150-151.

11. Food Standards Australia and New Zealand (2006) Final Assessment Report. Proposal P295. Consideration of Mandatory Fortification with Folic Acid. Canberra: FSANZ.

12. Australian Bureau of Statistics (1998) National Nutrition Survey: Nutrient Intakes and Physical Measurements. Australia, 1995. ABS Catalogue no. 4805.0. Canberra: ABS.

13. New Zealand Ministry of Health (1999) NZ Food: NZ People - Key Results of the 1997 National Nutrition Survey. Wellington: NZMoH.

14. Bower C, Blum L, O’Daly K, Higgins C, Loutsky F \& Kosky C (1997) Promotion of folate for the prevention of neural tube defects: knowledge and use of periconceptional folic acid supplements in Western Australia, 1992 to 1995. Aust N Z J Public Health 21, 716-721.

15. Centre for Reviews and Dissemination (2001) Undertaking Systematic Reviews of Research on Effectiveness: CRD's Guidance for Those Carrying Out or Commissioning Reviews. CRD Report no. 4, 2nd ed. York: University of York.

16. Australian Government, Department of Health and Ageing (2006) Medicare Benefits Schedule Book. Canberra: Commonwealth of Australia.

17. Carter R \& Scollo M (2000) Economic evaluation of the National Tobacco Campaign. In Australia's National Tobacco Campaign: Evaluation Report. vol. 2: Every Cigarette Is Doing You Damage, pp. 201-244 [K Hassard, editor]. Canberra: Commonwealth Department of Health and Ageing.

18. Australian Government (2005) Skin cancer awareness. Budget (2005-2006), Health Fact Sheet 1 - Investing in Australia's health: Strengthening Cancer Care. http:// www.health.gov.au/internet/budget/publishing.nsf/Content/ health-budget2005-hbudget-hfact1.htm (accessed March 2007).

19. Australian Government (2005) Go for $2 \& 5$ campaign. http://www.gofor2and5.com.au/campaign $\cdot$ asox?c $=5 \& \mathrm{a}=$ $83 \& \mathrm{t}=77 \& \mathrm{n}=50$ (accessed March 2007).

20. Cameron M, Haworth N, Oxley J, Newstead S \& Le T (1993) Evaluation of Transport Accident Commission Road Safety Television Advertising. MUARC Report no. 52. Victoria: Monash University Accident Research Centre.

21. Rapley M (2003) QoL in health and social care. In Quality of Life Research: A Critical Introduction, Ist ed., pp. 139-165. London: Sage Publications.

22. Stouthard MEA, Essink-Bot M-L \& Bonsel GJ, on behalf of the Dutch Disability Weights Group (2000) Disability weights for diseases: a modified protocol and results for a Western European region. Eur J Public Health 10, 24-30.

23. Department of Human Services, Public Health Division (1999) Victorian Burden of Disease Study: Morbidity. Melbourne: Department of Human Services.

24. Access Economics (2006) Cost benefit analysis of fortifying the food supply with folic acid. In Final Assessment Report. Proposal P295. Consideration of Mandatory Fortification with Folic Acid, pp. 20-21, attachment 11b. Canberra: FSANZ.

25. Australian Bureau of Statistics (2006) Population by Age and Sex, Australian States and Territories. ABS Catalogue no. 3201.0. Canberra: ABS.

26. Rowland CA, Correa A, Cragan JD \& Alverson CJ (2006) Are encephaloceles neural tube defects? Pediatrics 118, 916-923.

27. George B, Harris A \& Mitchell A (2001) Cost-effectiveness analysis and the consistency of decision making: evidence from pharmaceutical reimbursement in Australia (1991 to 1996). Pharmacoeconomics 19, 1-8.

28. Busby A, Abramsky L, Dolk H \& Armstrong BA (2005) Eurocat Folic Acid Working Group. Preventing neural tube defects in Europe: population based study. BMJ 330, $574-575$

29. Centers for Disease Control and Prevention (2008) Use of supplements containing folic acid among women of childbearing age - United States, 2007. MMWR Morb Mortal Wkly Rep 57, 5-8.

30. Lawrence JM, Watkins ML, Chiu V, Erikson JD \& Petitti DB (2006) Do racial and ethnic differences in serum folate values exist after food fortification with folic acid? $A m \mathrm{~J}$ Obstet Gynecol 194, 520-526.

31. Centers for Disease Control and Prevention (2008) Treated in wheat-flour fortification with folic acid and iron worldwide, 2004 and 2007. MMWR Morb Mortal Wkly Rep 57, 8-10.

32. Choumenkovitch SF, Selhub J, Wilson PWF, Rader JI, Rosenberg IH \& Jacques PF (2002) Folic acid intake from fortification in the United States exceeds predictions. $J$ Nutr 132, 2792-2798.

33. Centers for Disease Control and Prevention (2004) Spina bifida and anencephaly before and after folic acid mandate - United States, 1995-1996 and 1999-2000. MMWR Morb Moral Wkly Rep 53, 362-365.

34. Grosse SD, Waitzman NJ, Romano PS \& Mulinare J (2005) Reevaluating the benefits of folic acid fortification in the United States: economic analysis, regulation and public health. Am J Public Health 95, 1917-1922.

35. Pfeiffer CM, Johnson CL, Jain RB, Yetley EA, Picciano MF, Rader JI, Fisher KD, Mulinare J \& Osterloh JD (2007) Trends in blood folate and vitamin B-12 concentrations in the United States, 1988-2004. Am J Clin Nutr 86, 718-721.

36. De Wals P, Tairou F, Van Allen MI et al. (2007) Reduction in neural-tube defects after folic acid fortification in Canada. $N$ Engl J Med 357, 135-142.

37. Lopez-Camelo JS, Orioli IM, da Graca Dutra M et al. (2005) Reduction of birth prevalence rates of neural tube defects after folic acid fortification in Chile. Am J Med Genet A $\mathbf{1 3 5}$, $120-125$.

38. Chen LT \& Rivera MA (2004) The Costa Rican experience: reduction in neural tube defects following food fortification programs. Nutr Rev 62, 6 Pt 2, S40-S43.

39. Safdar OY, Al-Dabbagh AA, Abueliieneen WA \& Kari JA (2007) Decline in incidence of neural tube defects after the national fortification of flour (1997-2005). Saudi Med J 28, 1227-1229.

40. Daly LE, Kirke PN, Molloy A, Weir DG \& Scott JM (2005) Folate levels and neural tube defects: implications for prevention. JAMA 274, 1698-1702.

41. Dietrich M, Brown CJP \& Block G (2005) The effect of folate fortification of cereal-grain products on blood folate status, dietary folate intake, and dietary folate sources among adult non-supplement users in the United States. J Am Coll Nutr 24, 266-274.

42. Llanos A, Hertrampf E, Cortes F, Pardo A, Grosse SD \& Uauy R (2007) Cost-effectiveness of a folic acid fortification program in Chile. Health Policy 83, 295-303.

43. Jentik J, can de Vrie-Hoekstra NW, de Jong-van den Berg LT \& Postma MJ (2008) Economic evaluation of folic acid food fortification in The Netherlands. Eur J Public Health 18, 270-274.

44. Romano PS, Waitzman NJ, Scheffler RM \& Pi RD (1995) Folic acid fortification of grain: an economic analysis. $A m \mathrm{~J}$ Public Health 85, 667-676.

45. Postma MJ, Londeman J, Veenstra M, de Walle HEK \& de Jong- van den Berg LTW (2002) Cost effectiveness of periconceptional supplementation of folic acid. PharmWorld Sci 24, 8-11. 
46. Fenech M, Noakes M, Clifton P \& Topping D (1999) Aleurone flour is a rich source of bioavailable folate in humans. J Nutr 129, 1114-1119.

47. Tice JA, Ross E, Coxson PG, Rosenberg I, Weinstein MC, Hunick MG, Goldman PA, Williams L \& Goldman L (2001) Cost effectiveness of vitamin therapy to lower plasma homocysteine levels for the prevention of coronary heart disease: effect of grain fortification and beyond. JAMA 286, 936-943.

48. Hutubessy R, Chisholm D, Tan-Torres Edejer T \& WHOCHOICE (2003) Generalized cost-effectiveness analysis for national-level priority-setting in the health sector. Cost Eff Resour Alloc 1, 1-13.

49. Murray CJL, Evans DB, Acharya A \& Baltussen RMPM (2000) Development of the WHO guidelines on generalized cost-effectiveness analysis. Health Econ 9, 235-251.

50. Marsack CR, Alsop CL, Kurinczuk JJ \& Bower C (1995) Prepregnancy counselling for the primary prevention of birth defects: rubella vaccination and folate intake. Med J Aust 162, 403-406.

51. Chacko MR, Anding R, Kozinetz CA, Grover JL \& Smith PB (2003) Neural tube defects: knowledge and preconceptional prevention practices in minority young women. Pediatrics 112, 536-542.

52. Robbins JM, Cleves MA, Collins HB, Andrews N, Smith LN \& Hobbs CA (2005) Randomized trial of a physicianbased intervention to increase the use of folic acid supplements among women. Am J Obstet Gynecol 192, $1126-1132$.

53. Ashfield-Watt PAL, Whiting JM, Clark ZE, Moat SJ, Newcombe RG, Burr ML \& McDowell IFW (2003) A comparison of the effect of advice to eat either '5-a-day' fruit and vegetables or folic acid-fortified foods on plasma folate and homocysteine. Eur J Clin Nutr 57, 316-323.

54. Woolcott Research (2006) Research Report: Evaluation of the National Go For $2 \& 5$ Campaign. New South Wales: Woolcott Research.

55. de Walle HEK, van der Pal KM, de Jong-van den Berg LTW, Jeeninga W, Schouten JSAG, de Rover CM, Buitendijk SE \& Cornel MC (1999) Effect of mass media campaign to reduce socioeconomic differences in women's awareness and behaviour concerning use of folic acid: cross sectional study. BMJ 319, 291-292. 